\title{
Thermal Stability and Reproducibility Enhancement of Organic Solar Cells by Tris(hydroxyquinoline)gallium Dopant Forming a Dual Acceptor Active Layer
}

\author{
Fahmi F. Muhammad', Khaulah Sulaiman ${ }^{2}$ \\ ${ }^{1}$ Soft Materials and Devices Lab, Department of Physics, Faculty of Science and Health, Koya University, University Park, Danielle \\ Mitterrand Boulevard, Koya KOY45, Kurdistan Region - F.R. Iraq \\ ${ }^{2}$ Low Dimensional Materials Research Centre, Department of Physics, Faculty of Science, University of Malaya, 50603 Kuala Lumpur, \\ Malaysia
}

\begin{abstract}
Nowadays, the main barriers facing organic solar cells (OSCs) from being commercialized and widely applied are their weak thermal stability and reproducibility problems. To tackle these problems, researchers usually consider various strategies which include modification in the devices architectural design, utilizing low energy gap materials, functionalizing their active layers, and the use of various optimization procedures. In this research work, we are specifically focused on the utilization of a small molecular organometallic, tris(hydroxyquinoline)gallium (Gaq3), as a secondary acceptor dopant, aiming at improving thermal stability, and reproducibility of OSCs. All-solution processed technique with the help of spin coater was used to deposit the active layer of the devices. Results showed that the addition of $29 \%$ molar fraction of Gaq3 into the devices active layer has considerably improved the thermal stability, photo-absorption, and reproducibly of the solar cells thanks to the excellent thermal stability and electron mobility of Gaq3 molecules. Our devices based on DH6T: PCBM:Gaq3 performed highest stable performance at $180^{\circ} \mathrm{C}$, implying higher thermal stability compared to that of the reported P3HT: PCBM:F8BT and PTB7:PCBM: F8BT based solar cells. In spite of improved reproducibility, the efficiency of the devices was increased by 5.8 times compared to that of the control ones.
\end{abstract}

Index Terms-Active layer, dual acceptor, Gaq3 dopant, organic solar cell, reproducibility, Thermal stability.

\section{INTRODUCTION}

The detrimental effect on the environment and human life due to the long-term use of fossil fuels, oils, and natural

ARO-The Scientific Journal of Koya University Volume VI, No 2(2018), Article ID: ARO.10491, 10 pages DOI: 10.14500 /aro.10491

Received 01 December 2018; Accepted 27 December 2018

Regular research paper: Published 30 December 2018

Corresponding author's e-mail: fahmi.fariq@koyauniversity.org

Copyright (C) 2018 Fahmi F. Muhammad, Khaulah Sulaiman. This is an open-access article distributed under the Creative Commons Attribution License. gases demands the involvement of alternative clean and nonharmful resources, such as solar energy, in the production of electricity. Photovoltaic (PV) technology is successfully utilized to convert sunlight energy into electricity by means of solar cells comprising various architectural designs and active materials (Elumalai et al., 2016; Mathew et al., 2014; Muhammad et al., 2018; Schmager et al., 2019; Zhao et al., 2017a). The straightforward installation and low maintenance costs of solar electricity compared to that of other electricity sources make PV technology more convenient and attractive. It has been reported by the United Nations Development Programme in 2000 that the yearly potentiality of solar radiation flux is 1575-49837 exajoules (EJ), while the upper atmosphere of earth encounters 174,000 terawatts of solar energy flux (Johansson et al., 2012). This is much higher than the entire energy utilization around the globe, which was 559.8 EJ in 2012 (Ansari et al., 2018).

At present, the first and second generations of solar cells which are based on inorganic active materials are predominating the PV market, with power conversion efficiencies of up to $25 \%$, but they are expensive enough to be able to compete with the classical energy sources. Alternately, the third generation solar cells, namely organic solar cells (OSCs), dye-sensitized solar cells, and perovskite solar cells (PSCs), have received great attention over the past years due to their solution processability, low cost, flexibility, and their large-scale applications (Elumalai et al., 2016; Marinova et al., 2017; Mathew et al., 2014; Schmager et al., 2019). Third generation solar cells have now achieved a substantial decline in the production price of solar cells by $75 \%$ within less than a decade. The power conversion efficiency of OSCs has been significantly increased over the past decades from $1 \%$ in 1986 (Tang, 1986) to 5\% in 2005 (Xue et al., 2005), and more recently to up to $13 \%$ thanks to the molecular optimization and the use of non-fullerene acceptors in their active materials (Zhao et al., 2017a). However, the main problems of these devices are their limited thermal stability and short lifetime which considered to be a real obstacle in front of their commercialization and 
their wide application. To compete OSCs with traditional non-OSCs, efficiencies of $>15 \%$ and competitive stability are required. The unique features of organic materials making them attractive for OSCs are their optoelectronics tunability, light weight, flexibility, and high absorption coefficient (Liang et al., 2009; Muhammad and Sulaiman, 2011; Kaltenbrunner et al., 2012). The active layer of the device (the component which is responsible for solar energy absorption) is generally composed of two types of semiconducting materials which are n-type (electron acceptor) and p-type (electron donor). There should be a well-aligned energy band levels and viable miscibility between both donor (D) and acceptor (A) components to facilitate efficient charge transfer (CT) between the D-A moieties (Sehati et al., 2010; Treat et al., 2011). When sunlight strikes the donor component, photoinduced excitons (bounded electron-hole) are generated and are moved toward the boundary of D-A, where CT states are accumulated. Consequently, the bounded electrons and holes are dissociated into free charge carriers, whereby electrons are migrated from the lower unoccupied molecular orbital (LUMO) of the donor to that of the acceptor and holes are travelled from the higher occupied molecular orbital (HOMO) of the acceptor to that of the donor in a reverse direction (Sehati et al., 2010) (Fig. 1c). Finally, these free charges are, respectively, collected by the cathode and anode electrodes, thereby realizing a prototype OSC system (Fig. 1a).

It has been found in literature that various approaches and strategies were taken by researchers aiming at improving the overall performance of OSCs (Muhammad, 2014). Among these are bulk heterojunction, tandem and ternary structures which were developed to increase the D-A interfaces and hence improving the $\mathrm{CT}$ process compared to that of the bilayer D-A structure (Dennler et al., 2009; Peterson et al., 2011; Mulherin et al., 2011; Ameri et al., 2009; Muhammad and Sulaiman, 2011b). However, the response of basic electrical parameters governing the performance of these devices has not yet been fully understood (Huajun et al., 2014; Street et al., 2013). Minxia et al. utilized different organic solvents to improve the performance of ternary OSCs (Minxia et al., 2015) and Peterson et al. included inorganic nanoparticle to enhance the performance of these devices (Peterson et al., 2011). Thermal annealing process was also considered for the ternary OSCs based on two-donor incorporated OSCs having active layers of P3HT: PCBM:F8BT (Kim et al., 2009) and PTB7:PCBM: F8BT (Shang et al., 2015). Very recently, the concept of dual acceptor incorporated active layers has been also suggested to enhance the light absorption and CT properties of OSCs (Muhammad et al., 2017b; Zhao et al., 2017b; Liu et al., 2016), whereas the use of non-fullerene based acceptors was found to show a prominent enhancement of efficiency (Zhao et al., 2017a). Besides, various newly synthesized materials and design approaches were reported to better tackle the stability problem and to achieve higher stable devices (Reddy et al., 2016; Cheng and Zhan, 2016; Song et al., 2005; Zhu et al., 2011; Hau et al., 2008).

Gaq3 is a well-known small molecular organometallic material with interesting optoelectronics properties, photonic response selectivity, and thermal stability (Muhammad et al., 2010; Muhammad and Sulaiman, 2011d; Muhammad et al., 2016; Hernández et al., 2009; Muhammad and Sulaiman, 2011a). The use of $\mathrm{Gaq}_{3}$ has been widely dedicated for organic light emitting diodes/displays, but its utilization was also extended for solution-processed OSCs (Muhammad et al., 2017b). Incorporation of small molecular materials into the active layer of OSCs is of current research interests (Liu et al., 2015; Ji et al., 2016) due to the distinct optoelectronics features offered by these materials. Benefited by thermal stability and electron mobility of Gaq3, and

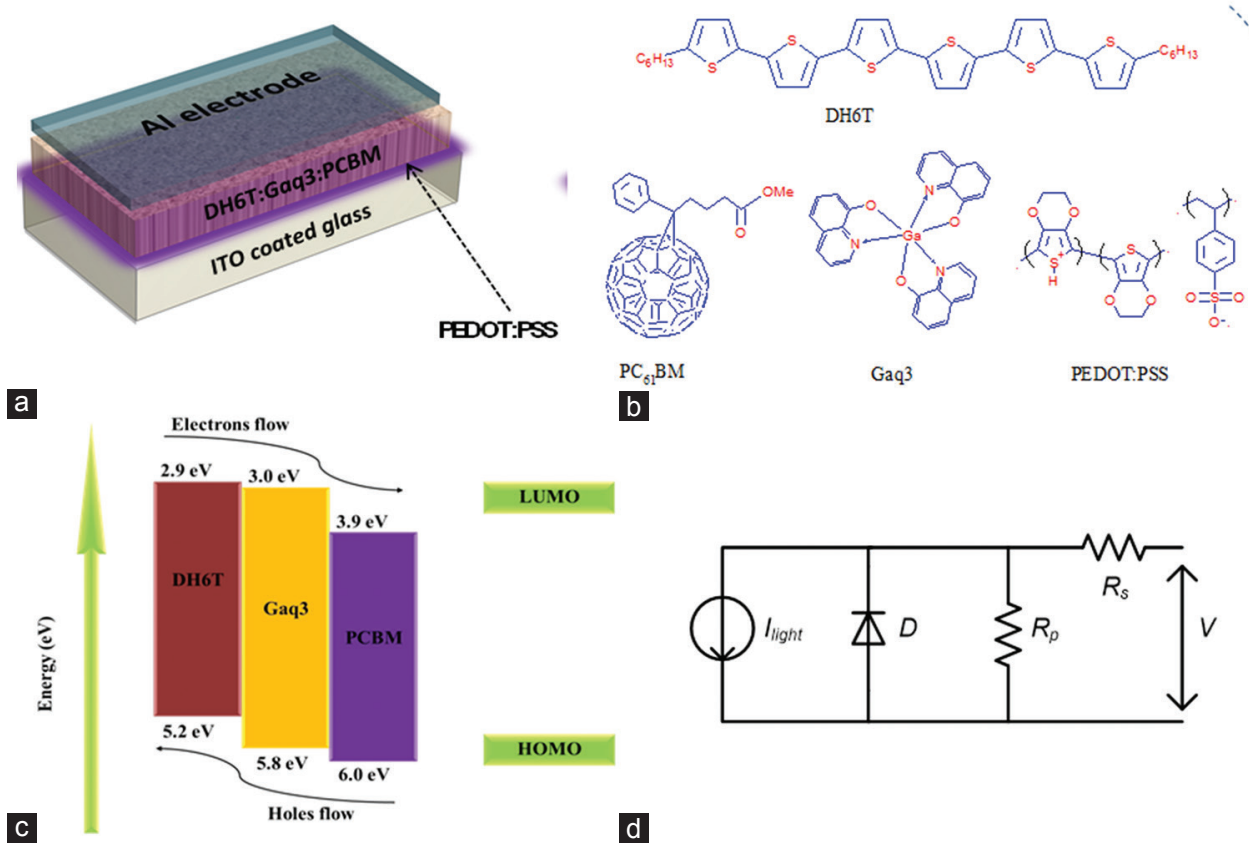

Fig. 1. The studied organic solar cells design (a), materials structure (b), higher occupied molecular orbital-lower unoccupied molecular orbital energy levels (c), and simulated equivalent circuit (d) of DH6T: PCBM:Gaq3 active layer. 
relatively close values of charge carrier mobility for $\alpha, \omega-$ dihexyl-sexithiophene (DH6T) donor and methano-fullerene $\left(\mathrm{PC}_{61} \mathrm{BM}\right)$ acceptor (Garnier et al., 1993; von Hauff et al., 2005; Muhammad and Sulaiman, 2011a; Muhammad et al., 2016), it is believed that the dispersion of a specified molar fraction of Gaq3 as a secondary acceptor dopant into the active layer of OSCs can have a great impact on the improvement of stability, reproducibility, and overall performance of these devices. Hence, in the current work, an optimum amount of Gaq3 is used to dope the active layer of OSCs comprising a dual acceptor, PCBM and Gaq3, that is aiming at maximizing the operation stability and reproducibility of the devices. The rest of the paper is organized as follows: In Section 2, the raw materials and methodology of the active layer preparation and characterization along with devices fabrication and assessment are given, whereas in Section 3 the achieved results are analyzed and discussed in detail. Finally, the main conclusions are drawn and presented in Section 4.

\section{Materials AND Methods}

The raw organic materials were purchased from SigmaAldrich (Malaysia Branch) in powder form and used as received without further purification. The OSC design, the molecular structure of the materials, their HOMO and LUMO energy levels along with an equivalent circuit to represent OSCs are shown in Fig. 1a-d, respectively. Poly(3,4-ethylenedioxythiophene):poly(4-styrenesulfonic) acid (PEDOT: PSS) was coated onto the anode electrode, indium tin oxide (ITO) to facilitate enhanced hole transport and to block the free electrons moving toward ITO. DH6T was utilized as the donor component, whereas the acceptor molecules were PCBM and Gaq3, respectively. To choose an optimum amount of Gaq3 to be doped into the device active layer, optical absorption studies of DH6T: Gaq3 system was initially performed.

The ITO (sheet resistance $\sim 10 \Omega / \mathrm{sq}$ ) coated glass substrates (H. W. Sands Co., Ltd.) were cut into square shapes and patterned accordingly in a wet etching process using a bath of hydrochloric acid and distilled water (0.4:1) at temperature $60^{\circ} \mathrm{C}$ for $15 \mathrm{~min}$. The PEDOT: PSS (from H. C. Starck, Baytron P VPAI 4033) was spin-coated onto the ITO at $3000 \mathrm{rpm}$ for $20 \mathrm{~s}$, then baked at $130^{\circ} \mathrm{C}$ for $5 \mathrm{~min}$ to achieve a thickness of $\sim 35 \mathrm{~nm}$. Then, the active layer mixture of DH6T: PCBM:Gaq3, having concertation of $30 \mathrm{mg} / \mathrm{ml}$, was dissolved in chlorobenzene and stirred overnight in the vials. Thin layer of DH6T: PCBM:Gaq3 (about $200 \mathrm{~nm}$ ) was spin-coated onto the PEDOT: PSS layer followed by thermal deposition of aluminum $(\sim 50 \mathrm{~nm}$ thick) under a vacuum of about $10^{-5 \mathrm{~m}}$ bar. In this way, four identical devices were fabricated on a single substrate batch. The area of active layers was $14 \mathrm{~mm}^{2}(2 \mathrm{~mm} \times 7 \mathrm{~mm})$ for each device. To investigate thermal stability, the devices were thermally annealed on a temperature controlled hot plate under air ambient for $20 \mathrm{~min}$ in the range from 140 to $220^{\circ} \mathrm{C}$ with steps of $40^{\circ} \mathrm{C}$, whereas the reproducibility strength was assessed based on the electrical records of the four identical devices of the same batch. To analysis the PV performance of the devices, current density-voltage (J-V) measurement was recorded using Keithley 236 instrument under standard illumination $\left(100 \mathrm{~mW} / \mathrm{cm}^{2}\right)$ originated from an Oriel solar simulator-model 67005 with an AM $1.5 \mathrm{G}$ filter. The absorption spectra of the films were recorded using Jasco V-570 UV-visible-NIR spectrophotometer, whereas KLA Tensor P-6 surface profilometer instrument was used to measure the thicknesses of films. Differential Scanning Calorimetry (Q200 thermal analyzer) was utilized to record the thermal profile of Gaq3. Finally, field emission scanning electronic microscopy technique (FESEM, Quanta 200F) and transmission electron microscopy (TEM LEO LIBRA-120) were utilized to capture the morphology and molecular distribution of the films. The light-activated current source $\left(\mathrm{J}_{\text {light }}\right)$ depicts the amount of current generated in the cell when it is exposed to sunlight energy. From the electrical circuit, one can determine the net current as follows (Muhammad et al., 2017a):

$$
J=J_{\text {light }}-J_{s}\left[\exp \left(\frac{V+J_{s}}{n K_{B} T / q}\right)-1\right]-\frac{\left(V+J R_{s}\right)}{R_{p}}
$$

Where, $\mathrm{J}_{\mathrm{s}}$ is the saturation current of the diode under dark, $\mathrm{K}_{\mathrm{B}}$ is the Boltzmann's constant, $\mathrm{T}$ is the temperature in Kelvin, $\mathrm{q}$ is electron unit charge, $\mathrm{R}_{\mathrm{s}}$ and $\mathrm{R}_{\mathrm{p}}$ are the series and parallel resistances of the device, respectively.

\section{Results And Discussion}

The optimum amount of Gaq3 dopant to be added into the active layer system is selected based on the broadening strength of the absorption spectra of DH6T and its energy gap $\left(\mathrm{E}_{\mathrm{g}}\right)$ reduction. The measurement of energy gap was carried out using the well-known Tauc's equation as follows (Muhammad and Sulaiman, 2011d):

$$
\alpha h v=B\left(h v-\mathrm{E}_{\mathrm{g}}\right)^{\mathrm{n}}
$$

where, $\alpha=2.303 \mathrm{~A} / \mathrm{t}$, A is the absorbance and $\mathrm{t}$ is thickness (optical path) of the film/solution, $\mathrm{h}$ is Planck's constant, $v$ is the frequency of the absorbed photons, B is an energyindependent constant, and $\mathrm{E}_{\mathrm{g}}$ is the energy gap. The value of $\mathrm{n}$ in Equation 2 determines the type of optical transition during the photo-absorption process, $\mathrm{n}=1 / 2,3 / 2,2$, and 3 for direct allowed, direct forbidden, indirect allowed, and indirect forbidden transitions, respectively. Extrapolation of the linear part of curves $(\alpha \mathrm{h} v)^{2 / 3}$ versus hv at the point where $(\alpha h v)^{2 / 3}=0$ gives the value of $E_{g}$. The calculated energy gap of DH6T incorporated with molar fractions of Gaq3 is shown as inset of Fig. 2, whereas Fig. 2 shows the absorption spectra for DH6T: Gaq3 blends with a molar ratio of $0 \%, 12.4 \%$, $29.8 \%$, and $41.4 \%$ for Gaq3.

One can notice from the figures that the addition of Gaq3 resulted in a clear redshift in the absorption spectrum of DH6T, that is, shifting toward higher wavelength and reducing its energy gap. These are ascribed to a larger $\pi-\pi$ stacking overlap between molecules (Muhammad et al., 2016). However, the addition of $41.4 \%$ molar fraction of Gaq3 was seen to increase $E_{g}$ and to produce a blue shift in 


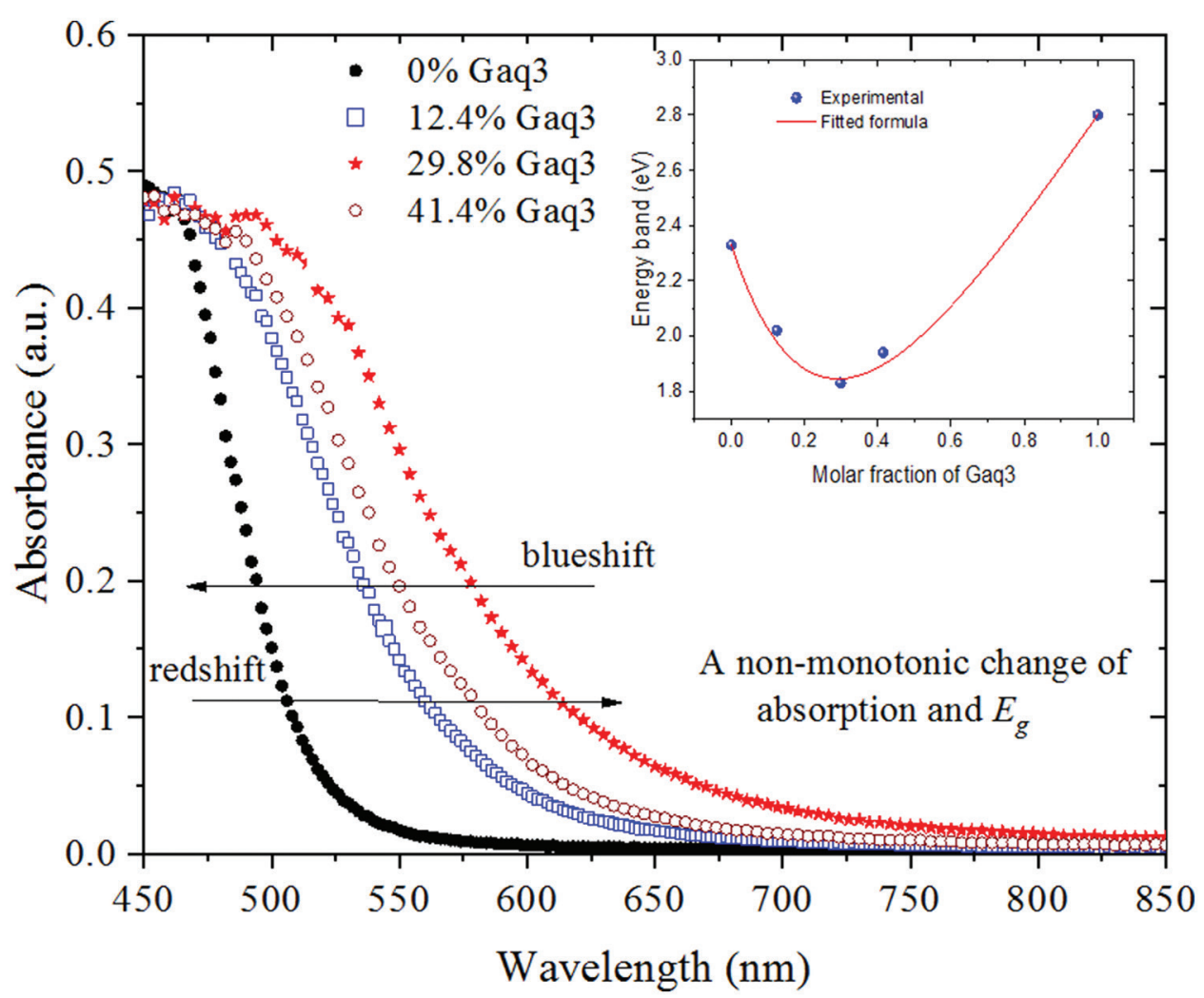

Fig. 2. Variation in the absorption spectra and energy gap of DH6T on the addition of various molar fractions of Gaq3.

the absorption spectrum. At $\mathrm{E}_{\mathrm{g}}$ photons are absorbed by the molecules and electrons are jumped from the ground energy state $\left(\mathrm{S}_{\mathrm{o}}\right)$ to the excited energy state $\left(\mathrm{S}_{1}\right)$, thereby transferring photo-energy between the D-A moieties. Therefore, the blueshifted $\mathrm{E}_{\mathrm{g}}$ at higher Gaq3 content is counted for the reduced $\pi-\pi$ stacking. This can be understood as the increased spatial geometry due to Gaq3 content acts on increasing the tail-tail rotational defect (Sotgiu et al., 2002), which, in turn, leads to a reduced intermolecular interaction and decreased $\pi-\pi$ orbital overlapping. To exactly identify the optimum amount of Gaq3 to be added in the next experimental steps during DH6T: PCBM:Gaq3 preparations, an empirical formula was derived, see Equation 3, by which the optimum molar fraction of Gaq3 was found to be 29\% (Fig. 2).

$$
\mathrm{E}_{\mathrm{g}}=\mathrm{E}_{\mathrm{g} 1}\left(\frac{1-\mathrm{x}}{1+\mathrm{Cx}}\right)+\mathrm{E}_{\mathrm{g} 2}\left(\frac{\mathrm{x}+\mathrm{Cx}}{1+\mathrm{Cx}}\right)^{2}
$$

Where, $\mathrm{C}$ is a numerical factor that was deduced to be 0.74. The terms $\mathrm{E}_{\mathrm{g} 1}, \mathrm{E}_{\mathrm{g} 2}$, and $\mathrm{x}$ define the energy gap of DH6T $(2.33 \mathrm{eV})$, Gaq3 $(2.80 \mathrm{eV})$, and the molar percentage of Gaq3, respectively.

Fig. 3 shows the normalized absorption spectra of DH6T, PCBM, Gaq3, and their mixture with 29\% molar fraction of Gaq3 in the DH6T: PCBM:Gaq3 active layer. Two characteristic absorption peaks at low and high wavelengths were detected for Gaq3 that is due to the orbital electronic transitions from $\mathrm{p}-\pi^{*}$ and $\pi-\pi^{*}$, respectively (Muhammad and Sulaiman, 2011d). The two peaks at 370 and $340 \mathrm{~nm}$ were assigned to DH6T and PCBM characteristic absorptions, respectively. These were found to be close enough to those reported in literature (Cook et al., 2007; Kwon and Seo, 2007). It is worth to notice that the absorption spectra of DH6T: PCBM were broadened compared to that of DH6T, implying an improved photoinduced CT from DH6T to PCBM (Koeppe and Sariciftci, 2006). Interestingly, the addition of $29 \%$ Gaq3 into the DH6T: PCBM active layer has led to a useful broadening in the absorption spectrum tailoring to about $720 \mathrm{~nm}$, where a vibronic shoulder was appeared. This vibronic peak can be directly correlated to the crystalline nature of the films as a result of the enhanced conjugation stacking and interchain interaction (Jo et al., 2009).

Fig. 4 shows the current density-voltage (J-V) characteristics of the OSCs based on DH6T: PCBM active layer with and without the addition of $29 \%$ molar fraction of Gaq3 that were tested in dark and under illumination conditions. Noticeably, the addition of Gaq3 molecules has increased the potential barrier $\left(\mathrm{V}_{\mathrm{f} 2}\right)$ of the device in dark situation, meaning that a larger D-A boundary has been generated, that is, an increased p-n junction barrier. Consequently, a higher open circuit voltage $\left(\mathrm{V}_{\mathrm{oc}}\right)$ is expected under light condition (see the solid blue triangle data points). The results showed a pronounced enhancement in the photocurrent and output voltage of the devices when Gaq3 is included. The short current density $\left(\mathrm{J}_{\mathrm{sc}}\right)$ was increased from $0.63 \mathrm{~mA}$ to $1.26 \mathrm{~mA}$ and the $\mathrm{V}_{\text {oc }}$ improved from 0.30 $\mathrm{V}$ to $0.74 \mathrm{~V}$. As such, the $\mathrm{J}_{\mathrm{sc}}$ and $\mathrm{V}_{\mathrm{oc}}$ were increased by an order of about 2 and 2.5, respectively. These increments are thought to be originated from a complementary enhancement of the photo-absorption ranging from $300 \mathrm{~nm}$ to about 


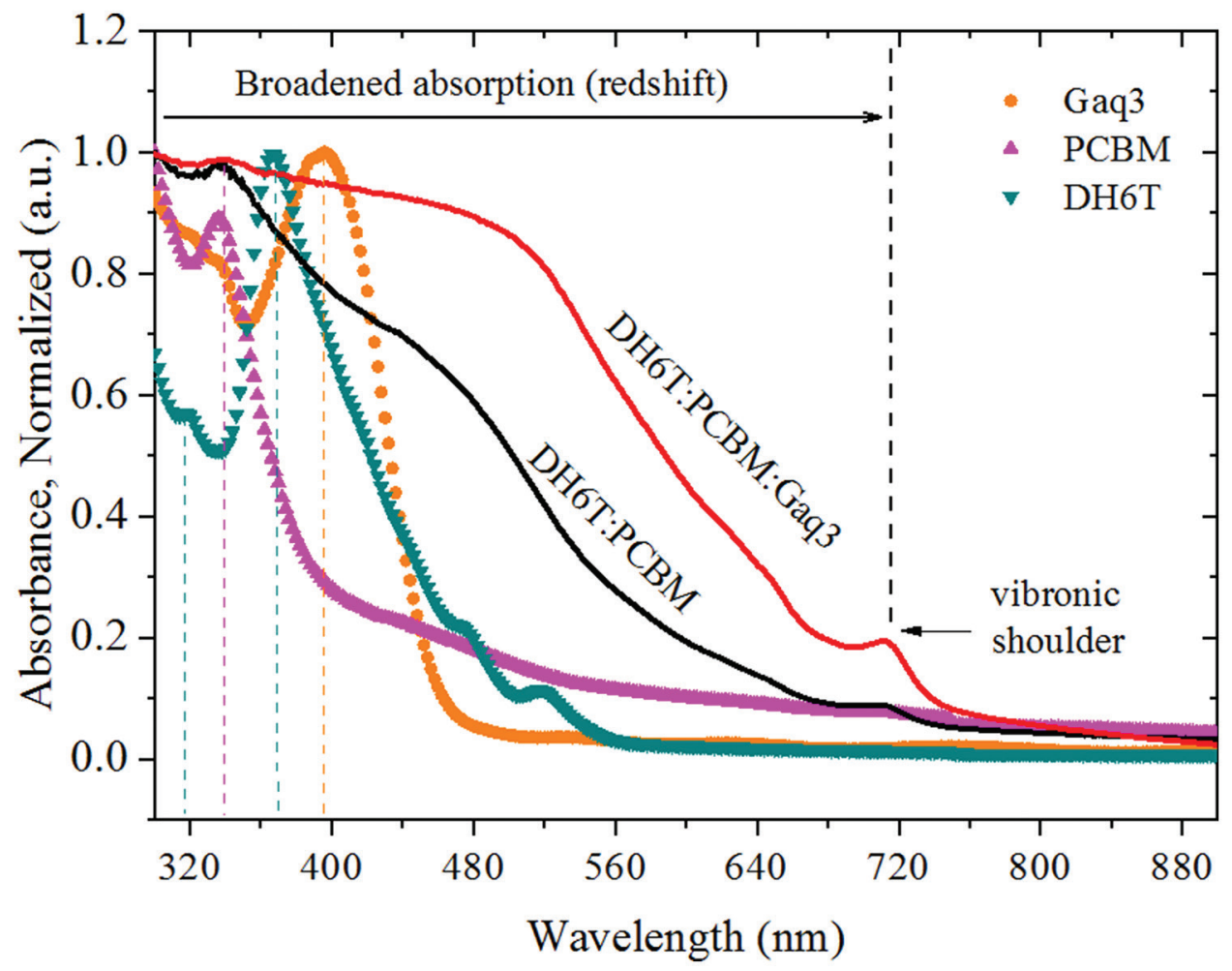

Fig. 3. Normalized absorbance of DH6T, PCBM, Gaq3, and their mixture with 29\% molar fraction of Gaq3 in the DH6T: PCBM:Gaq3 active layer.

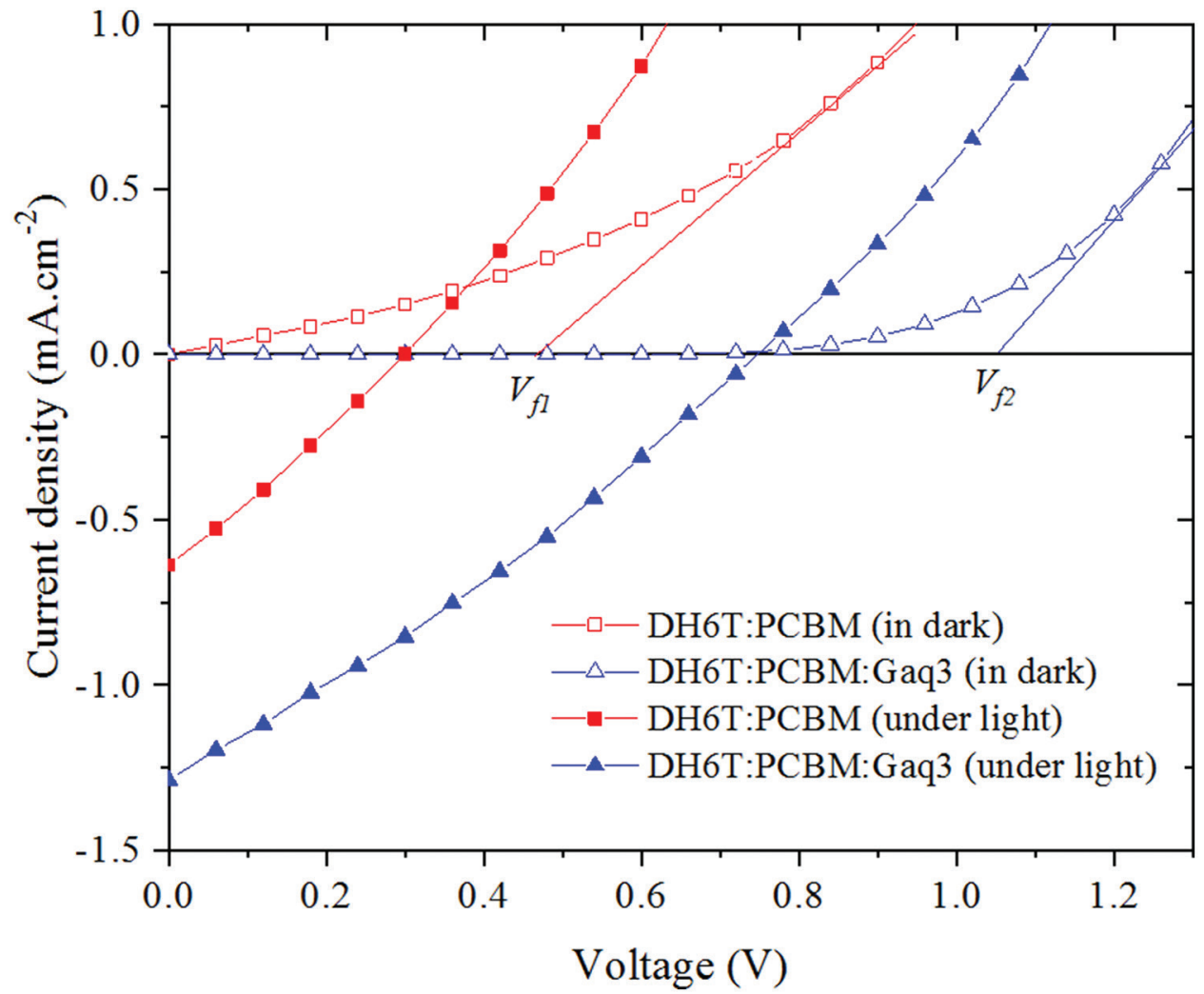

Fig. 4. The J-V characteristics of DH6T: PCBM:Gaq3 based organic solar cells incorporating 29\% of Gaq3.

$750 \mathrm{~nm}$, which was brought about by the inclusion of Gaq3 (Fig. 3). Referring to Fig. 1c, one can see that the HOMO and LUMO levels of the DH6T: Gaq3:PCBM system are well aligned to facilitate a smooth migration of free electrons and holes, thereby reducing the probability of electron-hole recombination at the D-A boundaries. 
Information on thermal stability of the OSCs was investigated through subjecting the devices to different annealing temperatures, ranging from room temperature $25^{\circ} \mathrm{C}$ to $220^{\circ} \mathrm{C}$. The performance of solar cells was assessed at each thermal condition, and their parameters were determined accordingly. It is seen from Fig. 5 that the $\mathrm{J}_{\mathrm{sc}}$ of the two-acceptor based solar cells was continuously increased by annealing temperatures up to $180^{\circ} \mathrm{C}$ but decreased by annealing at $220^{\circ} \mathrm{C}$. On the contrary, the $\mathrm{V}_{\mathrm{oc}}$ was found to be decreased with the rise of temperature to $140^{\circ} \mathrm{C}$, and then a subsequent increase in $\mathrm{V}_{\mathrm{oc}}$ was observed until the temperature has reached $220^{\circ} \mathrm{C}$. The same variation trend of the $\mathrm{J}_{\mathrm{sc}}$ and $\mathrm{V}_{\mathrm{oc}}$ on thermal annealing was also observed for the ternary OSCs comprising two-donor components such as P3HT: PCBM:F8BT (Kim et al., 2009) and PTB7:PCBM: F8BT (Shang et al., 2015), except that the point of inversion in the monotonic change of $\mathrm{J}_{\mathrm{sc}}$ for our devices was appeared at higher temperature of $180^{\circ} \mathrm{C}$ compared to that of the reported devices which were occurred at $120^{\circ} \mathrm{C}$. This indicated a higher thermal stability for our devices compared to that of the P3HT: PCBM:F8BT and PTB7:PCBM: F8BT based ones, which can be due to the effect of Gaq3 inclusion. We have previously reported that glass transition temperature $\left(\mathrm{T}_{\mathrm{g}}\right)$ for $\mathrm{Gaq} 3$ is about $182^{\circ} \mathrm{C}$
(Muhammad and Sulaiman, 2011a), which is close enough to the point of inversion in the $\mathrm{J}_{\mathrm{sc}}$ variation versus temperature, pointing out to the reasonable contribution of Gaq3 in the improvement of thermal stability of our devices.

Table I presents the PV and intrinsic parameters of the studied OSCs, which were extracted by fitting Equation 1 to the experimental $\mathrm{J}-\mathrm{V}$ data. One can see that the series resistance $\left(\mathrm{R}_{\mathrm{s}}\right)$ of the OSCs was decreased with the increase of temperature to up to $180^{\circ} \mathrm{C}$, whereas it was slightly increased at $220^{\circ} \mathrm{C}$. Comparably, it can be concluded that both $\mathrm{R}_{\mathrm{s}}$ and $\mathrm{J}_{\mathrm{sc}}$ are inversely proportioned each with other, which is in agreement with the theoretical reported results (Muhammad et al., 2017a). The decrease in $\mathrm{R}_{\mathrm{s}}$ is thought to be the consequence of increased crystallinity in the DH6T molecules on annealing, thereby improving photogenerated charge transport and percolation pathways in the devices active layer (Hwang et al., 2014). On the other hand, the decrease in $\mathrm{R}_{\mathrm{p}}$ with annealing temperature to about $180^{\circ} \mathrm{C}$ is evidenced to the relative increase in charge carriers' recombination. Noteworthy, the best performance for the OSCs based on DH6T: PCBM:Gaq3, that is, the dual acceptor based OSCs, was obtained at temperature of $180^{\circ} \mathrm{C}$, which is at higher temperature compared to those reported for the dual donor based devices (Sariciftci, 2004; Shang

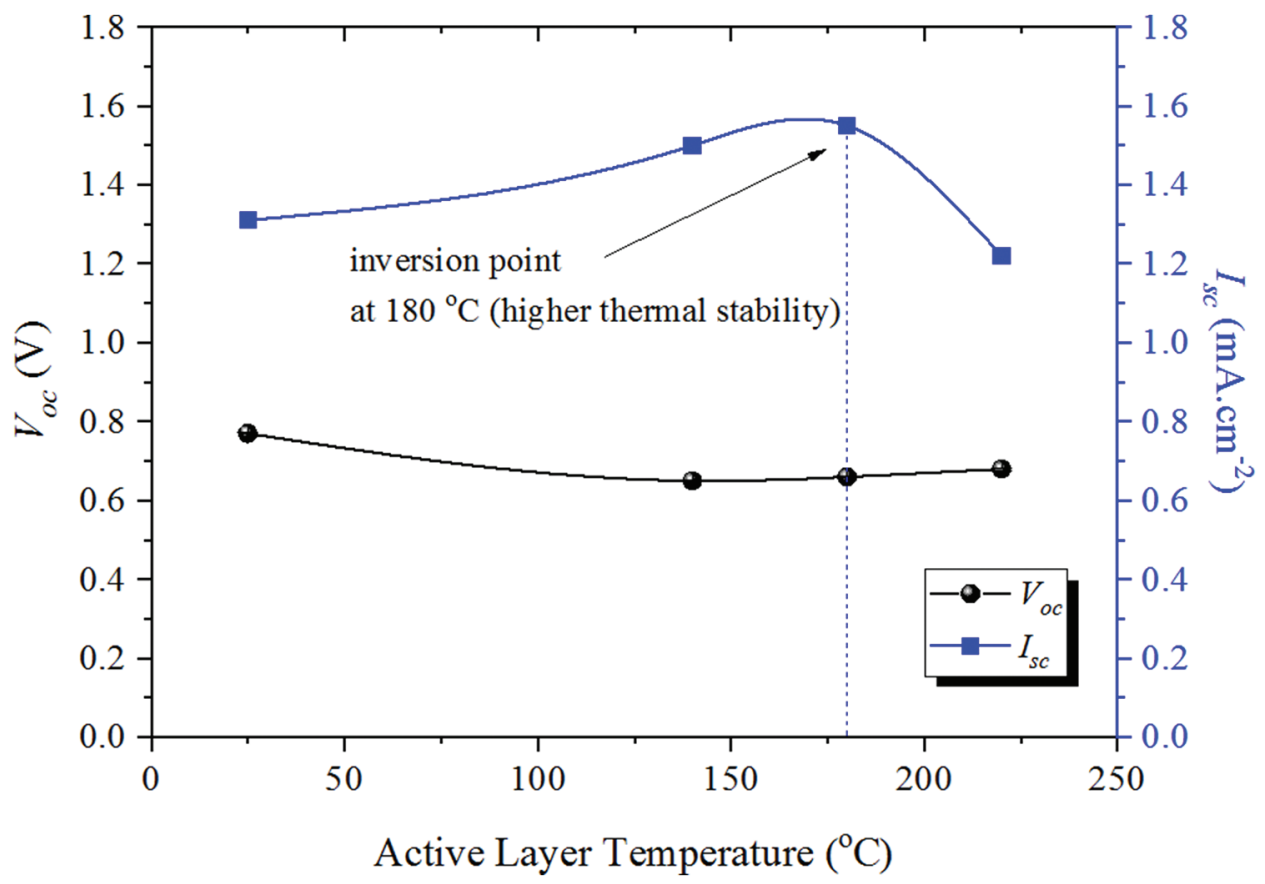

Fig. 5. Plot of $\mathrm{J}_{\mathrm{sc}}$ and $\mathrm{V}_{\mathrm{oc}}$ versus temperature for the organic solar cells based on DH6T: PCBM:Gaq3 active layer.

TABLE I

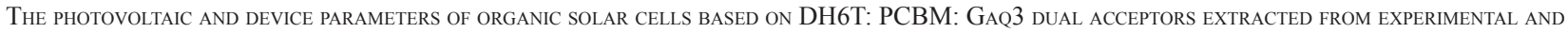
MODELING RESULTS

\begin{tabular}{|c|c|c|c|c|c|c|c|c|}
\hline Devices & Annealing $\mathrm{T}\left({ }^{\circ} \mathrm{C}\right)$ & $\mathrm{J}_{\mathrm{sc}} \cdot\left(\mathrm{mA} / \mathrm{cm}^{2}\right)$ & $\mathrm{V}_{\mathrm{oc}} \cdot(\mathrm{V})$ & $\mathrm{n}$ & $\mathrm{R}_{\mathrm{s}}(\Omega)$ & $\mathrm{R}_{\mathrm{p}}(\Omega)$ & $\mathrm{FF} \%$ & $\eta \%$ \\
\hline DH6T: PCBM & 25 & 0.63 & 0.30 & 3.81 & 887 & 5502 & 26.2 & 0.06 \\
\hline DH6T: PCBM: Gaq3 & 25 & 1.31 & 0.77 & 3.76 & 573 & 6775 & 26.7 & 0.27 \\
\hline DH6T: PCBM: Gaq3 & 140 & 1.50 & 0.65 & 2.23 & 367 & 4730 & 28.7 & 0.28 \\
\hline DH6T: PCBM: Gaq3 & 220 & 1.22 & 0.68 & 1.96 & 337 & 5814 & 26.5 & 0.22 \\
\hline
\end{tabular}


et al., 2015). This is another confirmation of high thermal stability for our devices thanks to the inclusion of small molecular Gaq3 acceptor. It is worth noting that the value of ideality factor (n) for the pristine devices is high and it gets reduced from 3.76 to 1.94 with the increase of annealing temperature to $180^{\circ} \mathrm{C}$. The close values of ideality factor to about two indicate that the charge carriers' recombination in these devices is governed by both of minority and majority carriers. It was generally observed that the efficiency of these devices was increased by order of 5.8 on the addition of Gaq3. Further enhancement in the efficiency, performance and stability of the OSCs can be achieved by taking the
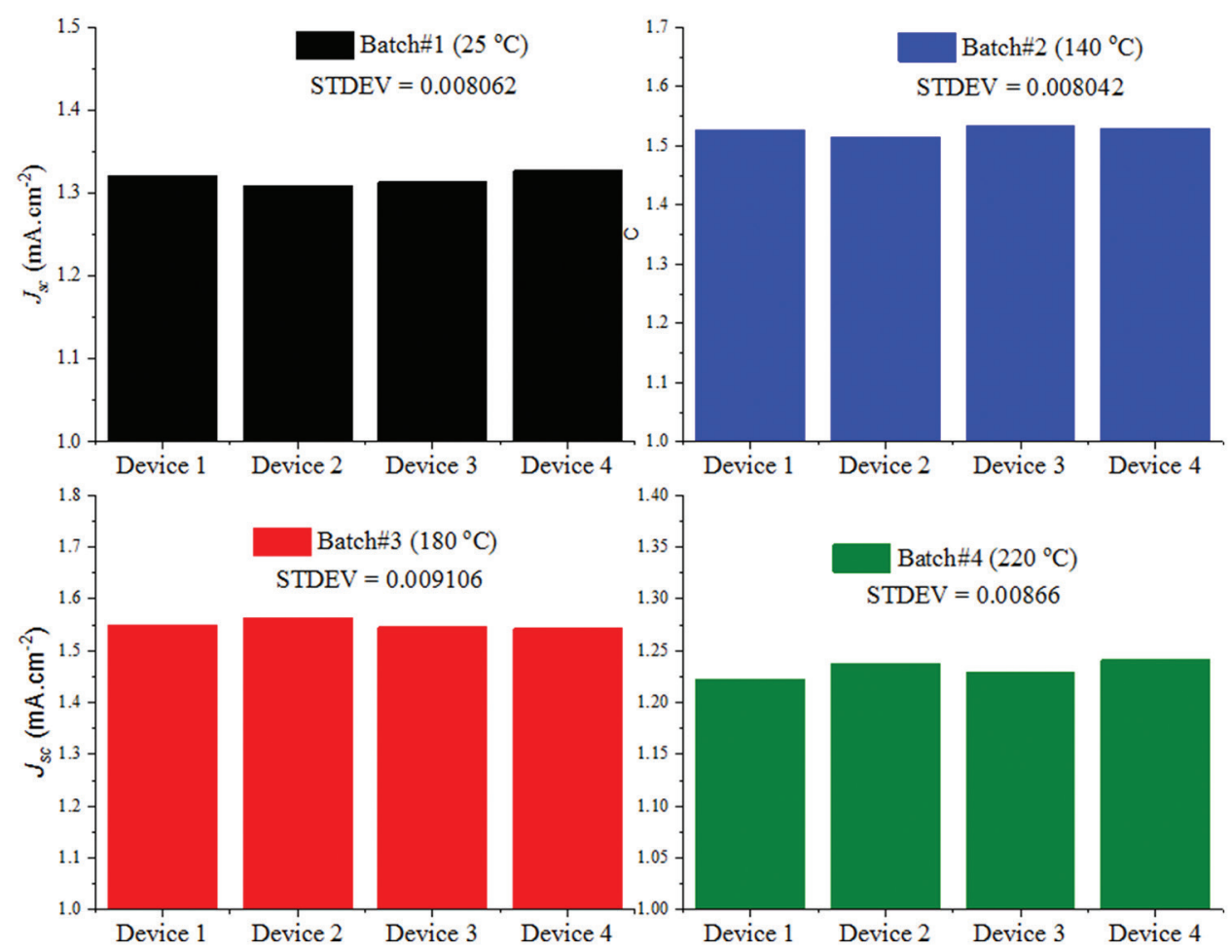

Fig. 6. Reproducibility comparison of the organic solar cells considering $\mathrm{J}_{\mathrm{sc}}$ variation among four different batches annealed at different temperatures.

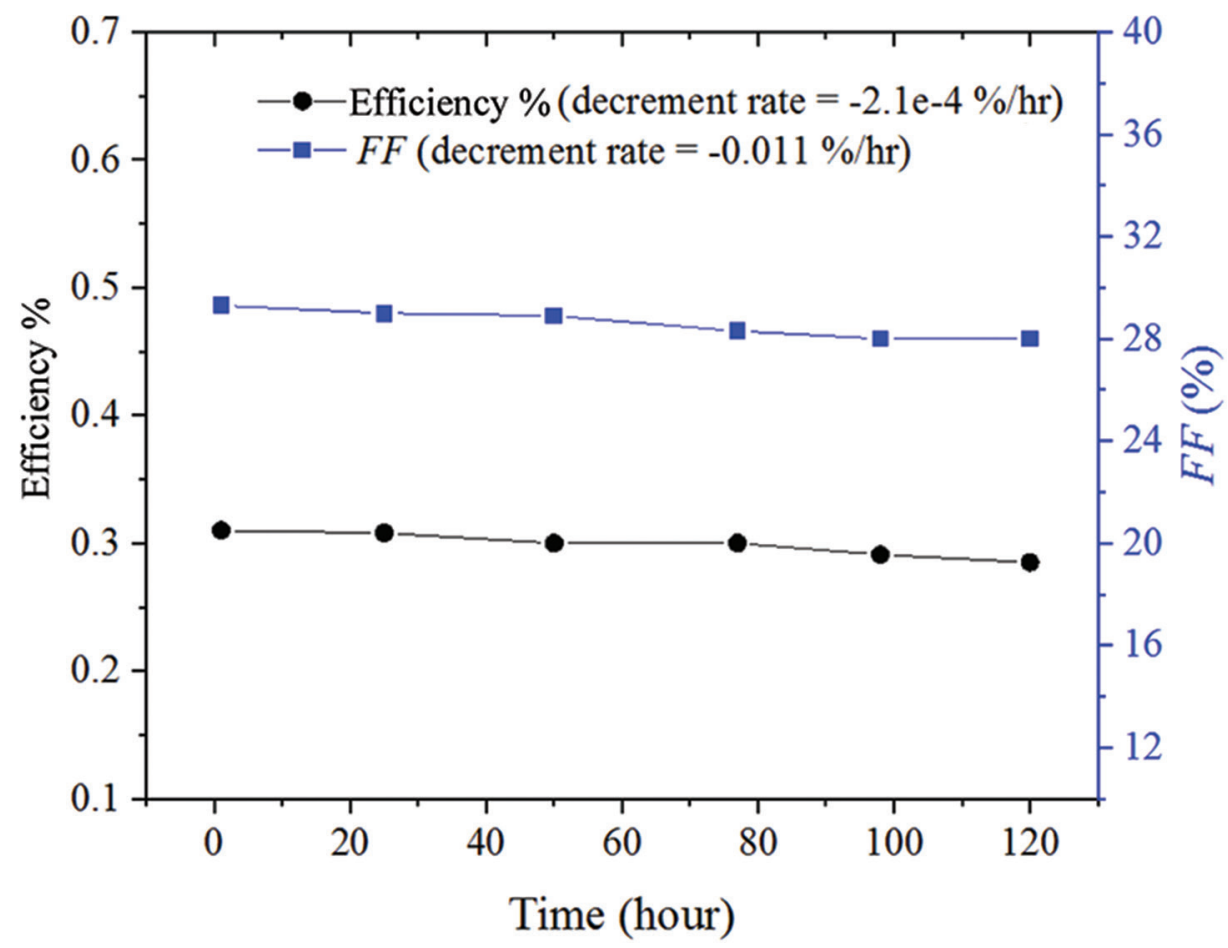

Fig. 7. The change in efficiency and fill factor for the studied organic solar cells in $120 \mathrm{~h}$ recorded within 6 consecutive days. 


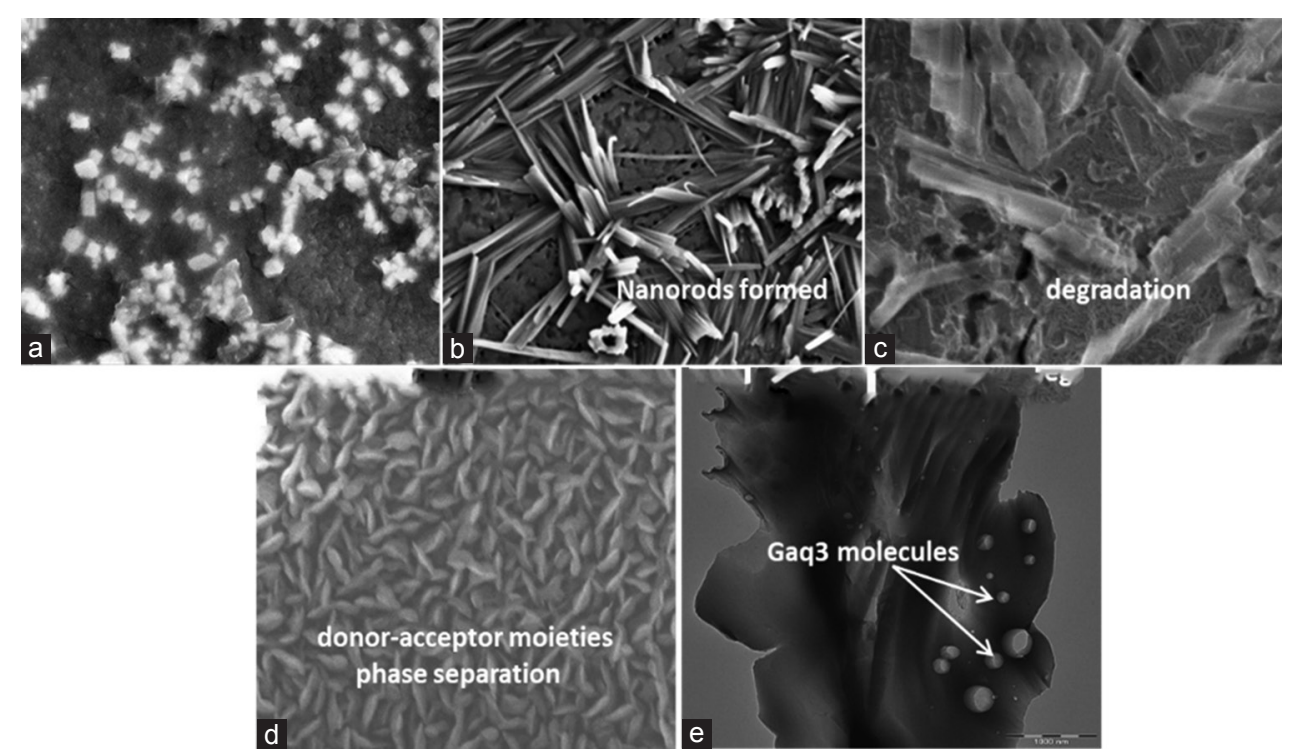

Fig. 8: Field emission scanning electronic microscopy images of Gaq3 film at room temperature $25^{\circ} \mathrm{C}$ (a), $180^{\circ} \mathrm{C}$ (b), $255^{\circ} \mathrm{C}$ (c), images of DH6T: Gaq 3 at room temperature $25^{\circ} \mathrm{C}(\mathrm{d}$ and e) and TEM image of the active layer based on DH6T: PCBM:Gaq3.

fabricating process inside glove box followed by the device's encapsulation. The current approach of using Gaq3 as the secondary acceptor can be generalized to the organic and PSCs aiming at improving their thermal stability and overall performance.

To reveal the impact of Gaq3 acceptor dopant on the reproducibility of the OSCs, the change in $\mathrm{J}_{\mathrm{sc}}$ was considered among four devices that were fabricated on the same substrate (a single batch). The fabrication process of each device was analogous and was carried out for similar materials and under similar environmental conditions. Four different batches (comprising four devices each) annealed at various temperatures were tested for their $\mathrm{J}_{\mathrm{sc}}$ parameter, as shown in Fig. 6. Results showed that the change in the $\mathrm{J}_{\mathrm{sc}}$ is trivial among four devices of each batch with standard deviations (STDEV) ranging from 0.008 to about 0.009 . This small deviation is a good indication of high reproducibility of the OSCs which was brought about by the high thermal stability of Gaq3 when it was used as a second acceptor in the OSCs.

To further elucidate the operational stability of the Gaq3 incorporated OSCs, the $\mathrm{J}-\mathrm{V}$ characteristics of the devices were recorded at different times within 6 consecutive days. Interestingly, it was noticed that the decrement in efficiency and fill factor of the devices over the studied time span are relatively small and almost similar performance was achieved for the devices, as shown in Fig. 7. The decrement rate was found to be $-2.1 \mathrm{E}-4 \%$ and $-0.011 \% / \mathrm{h}$ for the efficiency and fill factor, respectively.

Fig. 8a-e shows the surface and interface morphologies capture by FESEM and TEM for the Gaq3, DH6T: Gaq3 and DH6T: PCBM:Gaq3 films within $1 \mu(1000 \mathrm{~nm})$ resolution. It was seen that the surface morphology of Gaq3 start growing nanorods at temperature $180^{\circ} \mathrm{C}$ (Fig. 8-b). This temperature is close enough to the $\mathrm{T}_{\mathrm{g}}\left(182^{\circ} \mathrm{C}\right)$ of $\mathrm{Gaq} 3$, at which the material presents a rubbery state. We have seen previously that the OSCs showed the highest performance at this temperature, which might be due to the effect of Gaq3 distribution among DH6T: PCBM molecules. At a higher temperature of $255^{\circ} \mathrm{C}$, the nanostructures were degraded and no longer fortified (Fig. 8-c), suggesting good thermal stability of Gaq3 to be used in OSCs. One can see from Fig. 8-d and 8-e that the donor-acceptor components present a clear spatial distribution of the DH6T, Gaq3 and PCBM moieties, whereas the inclusion of Gaq3 molecules, positioned themselves in nanoballs stacking the active layer matrix at room temperature.

\section{Conclusions}

In this study, 29\% molar fraction of Gaq3 dopant was dispersed into the active layer of DH6T: PCBM to produce a solution-processed system having a dual acceptor to be used as the active layer of OSCs. It was concluded that the addition of Gaq3 resulted in a pronounced broadening in the absorption spectra of DH6T and DH6T: PCBM films. The results showed a pronounced enhancement in the photocurrent and output voltage of the devices when Gaq3 is included. The short current density $\left(\mathrm{J}_{\mathrm{sc}}\right)$ was increased from $0.63 \mathrm{~mA}$ to $1.26 \mathrm{~mA}$, and the $\mathrm{V}_{\text {oc }}$ improved from $0.30 \mathrm{~V}$ to $0.74 \mathrm{~V}$. As such, the $\mathrm{J}_{\mathrm{sc}}$ and $\mathrm{V}_{\mathrm{oc}}$ were increased by order of about 2 and 2.5, respectively. An inflection temperature of $180^{\circ} \mathrm{C}$ was noticed for $\mathrm{J}_{\mathrm{sc}}$ which was higher than that of the P3HT: PCBM:F8BT and PTB7:PCBM: F8BT based solar cells at $140^{\circ} \mathrm{C}$. This indicated higher thermal stability for our devices thanks to the effect of Gaq3 inclusion. It was generally observed that the efficiency of these devices was increased by an order of 5.8 on the addition of Gaq3. Four different batches (comprising four devices each) annealed at various temperatures were tested for their $\mathrm{J}_{\mathrm{sc}}$ parameter. Results showed that the change in the $\mathrm{J}_{\mathrm{sc}}$ is trivial among four devices of each batch with STDEV ranging from 0.008 to about 0.009 . This small deviation is a good indication of high reproducibility of the OSCs. The decrement rate of 
efficiency and fill factor of the devices over $120 \mathrm{~h}$ was found to be $-2.1 \mathrm{E}-4 \%$ and $-0.011 \% / \mathrm{h}$, respectively, which are small enough to conclude a stable operation of the devices. The surface morphology of Gaq3 start growing nanorods at temperature $180^{\circ} \mathrm{C}$. This temperature is close enough to the $\mathrm{T}_{\mathrm{g}}\left(182^{\circ} \mathrm{C}\right)$ of $\mathrm{Gaq} 3$, at which the material presents a rubbery state. The use of Gaq3 due to its good thermal stability can be potentially generalized to the other OSCs.

\section{ACKNOWLEDGMENTS}

The authors would like to thank University of Malaya to support this work under the project UMRG grant RP007A/13AFR.

\section{REFERENCES}

Ameri, T., Dennler, G., Lungenschmied, C. and Brabec, C.J., 2009. Organic tandem solar cells: A review. Energy and Environmental Science, 2, pp.347-363.

Ansari, M.I.H., Qurashi, A. and Nazeeruddin, M.K., 2018. Frontiers, opportunities, and challenges in perovskite solar cells: A critical review. Journal of Photochemistry and Photobiology C: Photochemistry Reviews, 35, pp.1-24.

Cheng, P. and Zhan, X., 2016. Stability of organic solar cells: Challenges and strategies. Chemical Society Reviews, 45, pp.2544-2582.

Cook, S., Ohkita, H., Kim, Y., Benson-Smith, J.J., Bradley, D.D.C. and Durrant, J.R., 2007. A photophysical study of PCBM thin films. Chemical Physics Letters, 445, pp.276-280.

Dennler, G., Scharber, M.C. and Brabec, C.J., 2009. Polymer-fullerene bulkheterojunction solar cells. Advanced materials, 21, pp.1323-1338.

Elumalai, N., Mahmud, M., Wang, D. and Uddin, A., 2016. Perovskite solar cells: Progress and advancements. Energies, 9, pp.861.

Garnier, F., Yassar, A., Hajlaoui, R., Horowitz, G., Deloffre, F., Servet, B., Ries, S. and Alnot, P., 1993. Molecular engineering of organic semiconductors: Design of self-assembly properties in conjugated thiophene oligomers. Journal of the American Chemical Society, 115, pp.8716-8721.

Hau, S.K., Yip, H.L., Baek, N.S., Zou, J., O'malley, K. and Jen, A.K.Y., 2008. Air-stable inverted flexible polymer solar cells using zinc oxide nanoparticles as an electron selective layer. Applied Physics Letters, 92, pp.225.

Hernández, I., Gillin, W. and Somerton, M., 2009. Spectroscopic study of Mq3 ( $\mathrm{M}=\mathrm{Al}, \mathrm{Ga}, \mathrm{In}, \mathrm{q}=8$-hydroxyquinolinate) at high pressure. Journal of Luminescence, 129, pp.1835-1839.

Huajun, X., Hideo, O., Hiroaki, B. and Shinzaburo, I., 2014. Open-circuit voltage of ternary blend polymer solar cells. Japanese Journal of Applied Physics, 53, pp.01AB10.

Hwang, I., Mcneill, C.R. and Greenham, N.C., 2014. Evolution of phase separation upon annealing and the influence on photocurrent generation in ternary blend organic solar cells. Synthetic Metals, 189, pp.63-68.

Ji, J., Ma, S., Shan, F., Wang, F. and Song, Y., 2016. Improving the performance of ternary bulk heterojunction polymer cell by regioregular poly (3-hexylthiophene)grafted oxide graphene on in situ doping of CdS. Journal of Materials Science, 51, pp.7395-7406.

Jo, J., Kim, S.S., Na, S.I., Yu, B.K. and Kim, D.Y., 2009. Time-dependent morphology evolution by annealing processes on polymer: Fullerene blend solar cells. Advanced Functional Materials, 19, pp.866-874.

Johansson, T.B., Patwardhan, A.P., Nakićenović, N. and GOMEZ-Echeverri, L. 2012. Global Energy Assessment: Toward a Sustainable Future. Cambridge University Press, Cambridge.
Kaltenbrunner, M., White, M.S., Głowacki, E.D., Sekitani, T., Someya, T., Sariciftci, N.S. and Bauer, S., 2012. Ultrathin and lightweight organic solar cells with high flexibility. Nature Communications, 3, pp.770.

Kim, H., Shin, M. and Kim, Y., 2009. Distinct annealing temperature in polymer: Fullerene: Polymer ternary blend solar cells. The Journal of Physical Chemistry C, 113, pp.1620-1623.

Koeppe, R. and Sariciftci, N.S., 2006. Photoinduced charge and energy transfer involving fullerene derivatives. Photochemical and Photobiological Sciences, 5, pp.1122-1131.

Kwon, J.H. and Seo, J.H., 2007. P-type semiconducting a,w-dihexylsexithiophene for an organic thin film transistor. Journal of Applied Physics, 101, pp.064502.

Liang, Y., Feng, D., Wu, Y., Tsai, S.T., Li, G., Ray, C. and Yu, L., 2009. Highly efficient solar cell polymers developed via fine-tuning of structural and electronic properties. Journal of the American Chemical Society, 131, pp.7792-7799.

Liu, L., Li, H., Yao, S., Wei, Y. and Tian, W., 2015. Synthesis, characterization, and photovoltaic properties of a solution-processable two-dimensionalconjugated organic small molecule containing a triphenylamine core. Journal of Materials Science, 50, pp.57-65.

Liu, T., Guo, Y., Yi, Y., Huo, L., Xue, X., Sun, X., Fu, H., Xiong, W., Meng, D. and Wang, Z., 2016. Ternary organic solar cells based on two compatible nonfullerene acceptors with power conversion efficiency $>10 \%$. Advanced Materials, 28, pp.10008-10015.

Marinova, N., Valero, S. and Delgado, J.L., 2017. Organic and perovskite solar cells: Working principles, materials and interfaces. Journal of Colloid and Interface Science, 488, pp.373-389.

Mathew, S., Yella, A., Gao, P., Humphry-Baker, R., Curchod, B.F., Ashari-Astani, N., Tavernelli, I., Rothlisberger, U., Nazeeruddin, M.K. and Grätzel, M., 2014. Dye-sensitized solar cells with $13 \%$ efficiency achieved through the molecular engineering of porphyrin sensitizers. Nature Chemistry, 6, pp.242.

Minxia, S., Xinge, Y., Xu, Y., Hanyu, W., Lei, Z., Quan, J. and Hui, L., 2015. Effect of different solvents on the performance of ternary polymer solar cells based on PTB7: PC71BM: F8BT. Journal of Physics D: Applied Physics, 48, pp.295105.

Muhammad, F.F. and Sulaiman, K., 2011a. Effects of thermal annealing on the optical, spectroscopic, and structural properties of tris (8-hydroxyquinolinate) gallium films grown on quartz substrates. Materials Chemistry and Physics, 129 , pp.1152-1158.

Muhammad, F.F. and Sulaiman, K., 2011b. Photovoltaic performance of organic solar cells based on DH6T/PCBM thin film active layers. Thin Solid Films, 519, pp.5230-5233.

Muhammad, F.F. and Sulaiman, K., 2011c. Tuning the optical band gap of DH6T by Alq3 dopant. Sains Malaysiana, 40, pp.17-20.

Muhammad, F.F. and Sulaiman, K., 2011d. Utilizing a simple and reliable method to investigate the optical functions of small molecular organic films-Alq3 and Gaq3 as examples. Measurement, 44, pp.1468-1474.

Muhammad, F.F., 2014. Design approaches to improve organic solar cells. Journal of Technology Innovations in Renewable Energy, 3, pp.63.

Muhammad, F.F., Hapip, A.I.A. and Sulaiman, K., 2010. Study of optoelectronic energy bands and molecular energy levels of tris (8-hydroxyquinolinate) gallium and aluminum organometallic materials from their spectroscopic and electrochemical analysis. Journal of Organometallic Chemistry, 695, pp. $2526-2531$.

Muhammad, F.F., Ketuly, K.A. and Yahya, M.Y., 2018. Effect of thermal annealing on a ternary organic solar cell incorporating Gaq3 organometallic as a boosting acceptor. Journal of Inorganic and Organometallic Polymers and Materials, 28, pp.102-109.

Muhammad, F.F., Yahya, M.Y. and Sulaiman, K., 2017b. Improving the performance of solution-processed organic solar cells by incorporating small molecule acceptors into a ternary bulk heterojunction based on DH6T: Mq3: 
$\operatorname{PCBM}(\mathrm{M}=\mathrm{Ga}, \mathrm{Al})$. Materials Chemistry and Physics, 188, pp.86-94.

Muhammad, F.F., Yahya, M.Y., Hameed, S.S., Aziz, F., Sulaiman, K., Rasheed, M.A. and Ahmad, Z., 2017a. Employment of single-diode model to elucidate the variations in photovoltaic parameters under different electrical and thermal conditions. PloS One, 12, pp.e0182925.

Muhammad, F.F., Yahya, M.Y., Ketuly, K.A., Muhammad, A.J. and Sulaiman, K., 2016. A study on the spectroscopic, energy band, and optoelectronic properties of $\alpha, \omega$-dihexylsexithiophene/tris (8-hydroxyquinolinate) gallium blends; DH6T/Gaq3 composite system. Spectrochimica Acta Part A: Molecular and Biomolecular Spectroscopy, 169, pp.144-151.

Mulherin, R.C., Jung, S., Huettner, S., Johnson, K., Kohn, P., Sommer, M., Allard, S., Scherf, U. and Greenham, N.C., 2011. Ternary photovoltaic blends incorporating an all-conjugated donor-acceptor diblock copolymer. Nano Letters, 11, pp.4846-4851.

Peterson, E.D., Smith, G.M., Fu, M., Adams, R.D., Coffin, R.C. and Carroll, D.L., 2011. Charge balance and photon collection in polymer based ternary bulk heterojunction photovoltaic devices containing cadmium selenide nanoparticles. Applied Physics Letters, 99, p.073304.

Reddy, S.S., Gunasekar, K., Heo, J.H., Im, S.H., Kim, C.S., Kim, D.H., Moon, J.H., Lee, J.Y., Song, M. and Jin, S.H., 2016. Highly efficient organic hole transporting materials for perovskite and organic solar cells with long-term stability. Advanced Materials, 28, pp.686-693.

Sariciftci, N.S., 2004. Plastic photovoltaic devices. Materials Today, 7, pp.36-40.

Schmager, R., Gomard, G., Richards, B.S. and Paetzold, U.W., 2019. Nanophotonic perovskite layers for enhanced current generation and mitigation of lead in perovskite solar cells. Solar Energy Materials and Solar Cells, 192, pp.65-71.

Sehati, P., Braun, S., Lindell, L., Xianjie, L., Andersson, L.M. and Fahlman, M., 2010. Energy-level alignment at metal-organic and organic-organic interfaces in bulk-heterojunction solar cells. IEEE Journal of Selected Topics in Quantum Electronics, 16, pp.1718-1724.

Shang, M., Yu, X., Ye, X., Zhang, L., Jiang, Q. and Lin, H., 2015. Effect of thermal annealing on the performance of ternary organic photovoltaics based on PTB7: PC71BM: F8BT. Journal of Materials Science: Materials in Electronics, 26, pp.5708-5714.

Song, Q., Li, F., Yang, H., Wu, H., Wang, X., Zhou, W., Zhao, J., Ding, X., Huang, C. and Hou, X., 2005. Small-molecule organic solar cells with improved stability. Chemical Physics Letters, 416, pp.42-46.

Sotgiu, G., Zambianchi, M., Barbarella, G. and Botta, C., 2002. Synthesis and optical properties of soluble sexithiophenes with one central head-to-head junction. Tetrahedron, 58, pp.2245-2251.

Street, R.A., Davies, D., Khlyabich, P.P., Burkhart, B. and Thompson, B.C., 2013. Origin of the tunable open-circuit voltage in ternary blend bulk heterojunction organic solar cells. Journal of the American Chemical Society, 135, pp.986-989.

Tang, C.W., 1986. Two-layer organic photovoltaic cell. Applied Physics Letters, 48, pp.183-185.

Treat, N.D., Brady, M.A., Smith, G., Toney, M.F., Kramer, E.J., Hawker, C.J. and Chabinyc, M.L. 2011. Interdiffusion of PCBM and P3HT reveals miscibility in a photovoltaically active blend. Advanced Energy Materials, 1, pp.82-89.

Von Hauff, E., Dyakonov, V. and Parisi, J., 2005. Study of field effect mobility in PCBM films and P3HT: PCBM blends. Solar Energy Materials and Solar Cells, 87, pp.149-156.

Xue, J., Rand, B.P., Uchida, S. and Forrest, S.R., 2005. Mixed donor-acceptor molecular heterojunctions for photovoltaic applications. II. Device performance. Journal of Applied Physics, 98, pp.124903.

Zhao, W., Li, S., Yao, H., Zhang, S., Zhang, Y., Yang, B. and Hou, J., 2017 a. Molecular optimization enables over 13\% efficiency in organic solar cells. Journal of the American Chemical Society, 139, pp.7148-7151.

Zhao, W., Li, S., Zhang, S., Liu, X. and Hou, J., 2017b. Ternary polymer solar cells based on two acceptors and one donor for achieving $12.2 \%$ efficiency. Advanced Materials, 29, pp.1604059.

Zhu, W., Wu, Y., Wang, S., Li, W., Li, X., Chen, J., Wang, Z.S. and Tian, H., 2011. Organic D-A- $\pi$-A solar cell sensitizers with improved stability and spectral response. Advanced Functional Materials, 21, pp.756-763. 